TITLE:

\title{
Living-Donor Lobar Lung Transplantation and Closure of Atrial Septal Defect for Adult Eisenmenger's Syndrome
}

\section{AUTHOR(S):}

Aokage, Keiju; Date, Hiroshi; Okazaki, Megumi; Sano, Yoshifumi; Oto, Takahiro; Kusano, Kengo; Goto, Keiji; Sano, Shunji; Miyoshi, Shinichiro

\section{CITATION:}

Aokage, Keiju ... [et al]. Living-Donor Lobar Lung Transplantation and Closure of Atrial Septal Defect for Adult Eisenmenger's Syndrome. Journal of Heart and Lung

Transplantation 2009, 28(10): 1107-1109

\section{ISSUE DATE:}

2009-10

URL:

http://hdl.handle.net/2433/87129

\section{RIGHT:}

c 2009 International Society for Heart and Lung Transplantation.; この 論文は出版社版でありません。引用の際には出版社版をご確認ご利用 ください。; This is not the published version. Please cite only the published version. 


\section{LIVING-DONOR LOBAR LUNG TRANSPLANTATION AND CLOSURE OF ATRIAL SEPTAL DEFECT FOR ADULT EISENMENGER'S SYNDROME}

Keiju Aokage, MDa, Hiroshi Date, MD ${ }^{b}$, Megumi Okazaki, RNª, Yoshifumi Sano, $\mathrm{MD}^{\mathrm{a}}$, Takahiro Oto, $\mathrm{MD}^{\mathrm{a}}$, Kengo Kusano, $\mathrm{MD}^{\mathrm{c}}$, Keiji Goto, $\mathrm{MD}^{\mathrm{d}}$, Shunji Sano, MD

Shinichiro Miyoshi, $\mathrm{MD}^{\mathrm{a}}$

From the aDepartment of Cancer and Thoracic Surgery, ${ }^{\mathrm{c} C a r d i o l o g y,}$ ${ }^{\mathrm{d} A n e s t h e s i o l o g y}$ and Resuscitology, ${ }^{\mathrm{e}}$ Cardiovascular Surgery, Okayama University Graduate School of Medicine, Dentistry and Pharmaceutical Sciences, Okayama; bDepartment of Thoracic Surgery, Kyoto University Graduate School of Medicine, Kyoto, Japan

Address for correspondence:

Hiroshi Date, MD

(Business)

Department of Thoracic Surgery, Kyoto University Graduate School of Medicine 54 Shogoin Kawahara-cho, Sakyo-ku, Kyoto 606-8507, Japan

TEL: $+81-75-751-3835 \quad$ FAX $+81-75-751-4647$

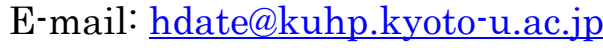

(Home)

507 De Lead Tetsugakunomichi, Higashida-cho-ichibanchi

Sakyo-ku, Kyoto 606-8411, JAPAN

TEL: +81-75-468-8979 FAX: +81-75-468-8979 


\section{ABSTRACT}

A 38-year-old woman with Eisenmenger's syndrome underwent bilateral living-donor lobar lung transplantation and simultaneous closure of atrial septal defect. The grafts were a right lower lobe from her husband and a left lower lobe from her brother. Although only two lobes were implanted, the dramatic improvement in pulmonary hemodynamics has been well maintained for more than 5 years. Living-donor lobar lung transplantation and simultaneous cardiac repair may be one of the therapeutic options for adult Eisenmenger's syndrome with simple congenital heart disease. 


\section{INTRODUCTION}

Lung or heart-lung transplantation remain the treatment of last resort for adult patients with Eisenmenger's syndrome who fail medical therapy. Living-donor lobar lung transplantation (LDLLT) was developed to mismatch between supply and demand for those patients awaiting cadaveric lung transplantation. ${ }^{1}$ We report the first successful LDLLT and simultaneous closure of atrial septal defect (ASD) for adult Eisenmenger's syndrome.

\section{CASE REPORT}

An adult female patient was diagnosed with ASD in her childhood but did not receive cardiac repair. In 1996, at the age of 31 years old, she delivered a normal baby. Soon after the delivery, symptoms of dyspnea occurred during exercise and she was diagnosed with Eisenmenger's syndrome. In 2001, at the age of 36, she further developed pulmonary thromboembolism and pulmonary infarction. In 2003, at the age of 38 , she became wheel chair bound and transferred to Okayama University Hospital for possible lung transplantation. On admission, she was markedly cyanotic and her arterial blood gas revealed a $\mathrm{pH}$ of $7.39, \mathrm{PaO}_{2}$ of $35.0 \mathrm{mmHg}$, and $\mathrm{PaCO}_{2}$ of $36.2 \mathrm{mmHg}$, with $3 \mathrm{~L} / \mathrm{min}$ oxygen administration via a nasal cannula. Chest X-ray showed dilated heart and pulmonary artery (PA) shadow (Figure 1A). The right heart catheterization performed a year ago revealed highly elevated pulmonary arterial pressure (systolic/diastolic/mean: 115/42/72). Two-dimensional echocardiography demonstrated a dilated dyskinetic right ventricle and D-shaped left ventricle. By color Doppler echocardiography, bidirectional shunt through the atrial septal defect with a diameter of $2.8 \mathrm{~cm}$ and massive tricuspid regurgitation were demonstrated. Enhanced CT scan showed enlarged pulmonary artery (PA), pulmonary thromboembolism and pulmonary infarction.

The surgical options were discussed with the patient and the family, and they were willing to proceed with LDLLT, which they understood to be the first case for adult 
Eisenmenger's syndrome. The case was carefully discussed and approved by the Lung Transplant Evaluation Committee at Okayama University Hospital.

On April 30, 2003, she underwent LDLLT at the age of 38, with a right lower lobe from her husband (36 years old) and a left lower lobe from her brother (34 years old). The height and weight was $146 \mathrm{~cm}, 40.2 \mathrm{~kg}$ for the recipient, $178 \mathrm{~cm}, 93.0 \mathrm{~kg}$ for the husband, and $169 \mathrm{~cm}, 74.0 \mathrm{~kg}$ for the brother. The total force vital capacity (FVC) of the two grafts was estimated to be $2,352 \mathrm{ml}$, or $89.8 \%$ of the recipient's predicted FVC according to the formula we have proposed. ${ }^{2}$

Because the patient's hemodynamics was unstable, cardiopulmonary bypass was instituted with bicaval venous drainage before completing the bilateral hilar dissection. Under cold cardioplegic arrest, the right atrium was opened. We closed the ASD, $25 \times 30 \mathrm{~mm}$, with a pericardial patch. After the aortic clamp was removed, bilateral pneumonectomy was performed. Pulmonary thromboemoblism was seen bilaterally distal to the first branch of PA which was removed at pneumonectomy. Two lobes were then implanted in the manner previously described. ${ }^{1}$ The PA anastomosis was challenging due to marked size discrepancy between the recipient's main PA and the donor's lobar PA. The recipient PA was partially closed by placing tacking stitches and then the end-to-end anastomosis was carried out. Cardiopulmonary bypass could be removed without any sign of lung edema after reperfusion.

Postoperative immunosuppresion was a triple drug therapy consisting of tacrolimus, mycophenolate mofetil and prednisone. Two episodes of acute rejection were successfully treated by steroid pulse. The patient was completely weaned from the respirator on day 22 and discharged from the hospital on day 48 without oxygen inhalation.

The dramatic improvement in pulmonary hemodynamics was seen one month after LDLLT and has been well maintained for more than 5 years (Table I). Her 
chest X-ray demonstrated well-expanded grafts without cardiomegaly (Figure 1B). Although she developed right unilateral bronchiolitis obliterans syndrome at 4 years, she is able to carry out normal activities for more than 6 years since she received the LDLLT.

Postoperative course was uneventful in both donors and they have returned to their previous life styles during the 6-year observation period.

\section{DISCUSSION}

There are three transplant options for Eisenmenger's syndrome; single lung transplantation (SLT), bilateral lung transplantation (BLT), and heart-lung transplantation (HLT). Cardiac repair with BLT $^{3}$ appears to have a better post-operative course than $\mathrm{SLT}^{4}$, but carries potential morbidity associated with longer cardiopulmonary bypass. HLT ${ }^{5}$ is a simpler operation than BLT with repair of congenital heart disease, but requires allocation of two organs from the scarce donor organ supply, and adds risk of cardiac graft coronary vasculopathy and is less tolerant of ischemic time.

LDLLT was pioneered by the University of Southern California group to deal with the shortage of cadaveric donors. ${ }^{1}$ They originally applied this procedure almost exclusively to cystic fibrosis patients and then expanded the indications to other diagnoses including pediatric patient with pulmonary arterial hypertension (PAH) ${ }^{6}$ Since 2000, we have applied this procedure to both pediatric and adult patients with PAH. ${ }^{7}$

It has been suggested that adults with Eisenmenger's syndrome have a more favorable hemodynamic profile and prognosis than adults with idiopathic PAH. ${ }^{8}$ In contrast, the 5-year survival after BLT or HLT remains to be approximately $50 \%$ according to the registry of ISHLT. ${ }^{9}$ Our patient with Eisenmenger's syndrome was critically ill due to associated pulmonary thromboembolism. The realistic option for this patient was only to receive LDLLT in Japan, where obtaining brain death 
donors is extremely difficult. The ethical concerns of LDLLT present an obvious dilemma. This procedure subjects two healthy donors to a right or left lower lobectomy associated with an expected risk of death between $0.5 \%$ to $1 \%$, a complication rate of $10-20 \%$, and the inevitable $15 \%$ reduction in pulmonary function. While there have been no deaths in the donor cohort, these disadvantages are to be carefully explained to the potential donors during the process of obtaining informed consent. Because of these ethical concerns, we accept only very sick patients as LDLLT recipients.

Because limited amount of lung tissue is implanted in LDLLT, size matching is an important issue. Matsuda and his colleagues reported successful LDLLT and simultaneous closure of ASD for an 11-year-old boy with irreversible pulmonary hypertension. ${ }^{10}$ The present case was the first successful LDLLT for adult Eisenmenger's syndrome. Luckily, our patient had two male donors who were taller than her and the total FVC of the two grafts was estimated to be $89.9 \%$ of the recipient's predicted FVC. Although only two lobes were implanted, the dramatic improvement in pulmonary hemodynamics has been well maintained for more than 5 years. Although her FEV1 decreased at 5 years due to right unilateral bronchiolitis obliterans syndrome, she is maintaining a good quality of life because her unaffected left graft is functioning normally.

LDLLT and simultaneous cardiac repair may be one of the therapeutic options for adult Eisenmenger's syndrome with simple congenital heart disease.

\section{Acknowledgement}

The authors have nothing to disclose on this article. 


\section{REFERENCES}

1. Starnes VA, Barr ML, Cohen RG. Lobar transplantation: indications, technique, and outcome. J Thorac Cardiovasc Surg. 1994; 108: 403-11.

2. Date H, Aoe M, Nagahiro I, et al. How to predict forced vital capacity after living-donor lobar-lung transplantation. J Heart Lung Transplant 2004; 23:547-51.

3. Choong CK, Sweet SC, Guthrie TJ, et al. Repair of congenital heart lesions combined with lung transplantation for the treatment of severe pulmonary hypertension: a 13-year experience. J Thorac Cardiovasc Surg 2005; 129:661-9.

4. Pasque MK, Trulock EP, Cooper JD, et al. Single lung transplantation for pulmonary hypertension. Circulation. 1995; 92: 2252-8.

5. Goerler H, Simon A, Gohrbandt B, et al. Heart-lung and lung transplantation in grown-up congenital heart disease: long-term single centre experience. Eur J Cardiothorac Surg 2007; 32:926-31.

6. Starnes VA, Bowdish ME, Woo MS, et al. A decade of living lobar lung transplantation. Recipient outcomes. J Thorac Cardiovasc Surg 2004; 127:114-22.

7. Date H, Kusano KF, Matsubara H, et al. Living-donor lobar lung transplantation for pulmonary arterial hypertension after failure of epoprostenol therapy. J Am Coll Cardiol 2007; 50: 523-7.

8. Hopkins WE, Ochoa LL, Richardson GW, Trulock EP. Comparison of the hemodynamics and survival of adults with severe primary pulmonary hypertension or Eisenmenger syndrome. J Heart Lung Transplant 1996; $15: 100-5$.

9. Christie JD, Edwards LB, Aurora P et al. Registry of the International Society for Heart and Lung Transplantation: Twenty-fourth official adult lung and heart-lung transplant report - 2008. J Heart Lung Transplant 2008; 27:957-69. 
10. Matsuda H, Minami M, Ichikawa H, et al. Living-related lobar transplantation adn simultaneous atrial septal defect closure in a young patient with irreversible pulmonary hypertension: a case report. Heart Vessels 2004; 19:203-7. 


\section{Figure Legend}

Figure 1. Chest X-ray of a 38-year-old female with Eisenmenger's syndrome. (A) Before transplantation. (B) One year after receiving bilateral living-donor lobar lung transplantation. 
TABLE 1. Patient data

\begin{tabular}{|lccccc|}
\hline & & \multicolumn{5}{c|}{ Posttransplant } \\
\cline { 3 - 6 } & Pretransplant & 2 months & 1year & 3 years & 5 years \\
\hline $\mathrm{PAP}(\mathrm{mmHg})$ & $115 / 44(72)$ & $36 / 12(20)$ & $32 / 9(17)$ & $23 / 6(13)$ & $16 / 10(13)$ \\
$\mathrm{PCWP}(\mathrm{mmHg})$ & 8 & 11 & 10 & 8 & 7 \\
$\mathrm{CVP}(\mathrm{mmHg})$ & 7 & 3 & 0 & 3 & 1 \\
$\mathrm{PaO}_{2}(\mathrm{mmHg})$ & $35.0\left(\mathrm{O}_{2} 3 \mathrm{~L} / \mathrm{min}\right)$ & 99.3 & 100.8 & 79.0 & 93.7 \\
$\mathrm{PaCO}_{2}(\mathrm{mmHg})$ & $36.2\left(\mathrm{O}_{2} 3 \mathrm{~L} / \mathrm{min}\right)$ & 42.4 & 33.2 & 33.7 & 39.2 \\
$\mathrm{VC}(\mathrm{mL})$ & 2310 & 1640 & 1800 & 2020 & 2200 \\
$\% \mathrm{VC}(\%)$ & 86.8 & 61.7 & 68.2 & 77.7 & 84.9 \\
$\mathrm{FEV}$ & $(\mathrm{mL})$ & 1510 & 1600 & 1790 & 1270 \\
$\mathrm{WHO}$ class & 1620 & $\mathrm{I}$ & $\mathrm{I}$ & $\mathrm{I}$ & $\mathrm{II}$ \\
\hline
\end{tabular}

$P A P$, pulmonary arterial pressure; $P C W P$, pulmonary capillary wedge pressure

$C V P$, central venous pressure; $\mathrm{PaO}_{2}$, arterial oxygen tension; $\mathrm{PaCO}_{2}$, arterial carbon dioxide tension

$V C$, vital capacity; FEV1, forced expiratory volume in one second 

